\title{
ОЦЕНКА ВЛИЯНИЯ ОТХОДОВ ПРЕДПРИЯТИЙ ШЕРСТЯНОГО ПРОИЗВОДСТВА НА ОКРУЖАЮЩУЮ СРЕДУ
}

\section{ASSESSMENT OF THE IMPACT OF WASTE FROM WOOL PRODUCTION ENTERPRISES ON THE ENVIRONMENT}

I. Chadova

Summary. The article presents the results of assessing the impact of wool production enterprises waste on the environment. Particular emphasis is placed on air and wastewater pollution. The characteristic of the toxicological effect of auxiliary substances and dyes during wool processing is also presented.

Keywords: wool, pollution, ecology, waste water, emissions.

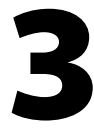
ащита окружающей среды и противодействие изменению климата - это не только признанная во всем мире политическая необходимость, но также и выгодная инвестиция в создание рабочих мест и более устойчивую экономику. Для достижения стабильного роста каждая страна должна обеспечить экологизацию существующих отраслей промышленности, поддержку и становление нового «зеленого» производства. «Зеленый» индустриальный сектор сокращает выбросы парниковых газов и загрязнения благодаря повышению энерго- и ресурсоэффективности, а также одновременно способствует сохранению биоразнообразия и услуг экосистем [1].

В тоже время активно развивающееся на сегодняшний день общество потребления не в полной мере готово перейти на ресурсосберегающие технологии и экологически чистое производство. Связано это с тем, например, что владение той или иной вещью стало не жизненной необходимостью, а признаком и мерилом жизненного успеха. Рыночная экономика заинтересована в быстрой смене модных циклов. Дизайнеры, создавая ту или иную вещь, заранее предусматривают быстрое старения модных трендов, чем провоцируют людей покупать одежду все чаще.

В свою очередь предприятия шерстяной промышленности, выпускающие одежду и предметы обихода, из-за специфики производства, несмотря на развитие техники и технологии, сталкиваются с проблемами экологичности. Связано это с тем, что изготовление

\author{
Чадова Инна Николаевна \\ К.б.н., дочент, Ставропольский Государственный \\ Аграрный Университет \\ innachadova@yandex.ru
}

Аннотация. В статье представлены результаты оценки влияния отходов предприятий шерстяного производства на окружающую среду. Особый акцент сделан на загрязнении атмосферы и сточных вод. Также представлена характеристика токсикологического воздействия вспомогательных веществ и красителей при обработке шерсти.

Ключевые слова: шерсть, загрязнение, экология, сточные воды, выбросы.

шерстяных изделий включает различные физические и химические процессы, поэтому от вида шерсти и характера ее обработки зависит серьезность и тяжесть воздействия технологических процессов на окружающую среду и здоровье человека. Для шерстяного производства характерно не только потребление больших объемов воды, но и использование различных абразивных веществ [2]. Существует целый ряд процессов химической обработки, для которых необходима вода, химические ингредиенты и электроэнергия. Все это влечет за собой образование отходов. Характер отходов зависит от типа производства, использованных волокон и особенностей технологических процессов.

В данном контексте особую актуальность и значимость приобретает исследование воздействия предприятий шерстяной промышленности на воздушный и водный бассейн, а также на жизнь и здоровье людей, с конкретными примерами видов загрязнений и современными методами борьбы с ними, что в целом предопределяет выбор темы данной статьи, а также подтверждает ее теоретическую и практическую значимость.

Значительное внимание изучению и исследованию технологий изготовления шерстяных изделий в направлении их экологизации уделяют различные ученые. О глубокой проработанности данной проблематики свидетельствуют, в частности, труды таких авторов, как: Исламова 3.Ш., Амирова Н.С., Набиева И.А., Wang, Wanlin; Dai, Shifan; Zhang, Tongsheng; Zhang. 
Таблица 1. Характеристика токсикологического воздействия вспомогательных веществ и красителей при обработке шерсти

\begin{tabular}{|c|c|c|}
\hline Продукт & Применение в производстве & Негативный эффект \\
\hline Диспергаторы & Колорирование & Изменение санитарного состояния водоемов \\
\hline Смягчители & Окончательная обработка & Изменение органолептических свойств воды \\
\hline Прошивные агенты & \multirow{3}{*}{ Пигментная печать } & $\begin{array}{l}\text { Неприятный запах и вкус воды, снижение } \\
\text { биохимического процесса окисления }\end{array}$ \\
\hline Отделочные агенты & & Токсическое воздействие на ил \\
\hline Гидрофобизаторы & & Заболевания различной природы \\
\hline Ароматические амины & Составляющие красителей & Канцерогенное воздействие \\
\hline Хлорированные углеводороды & $\begin{array}{l}\text { Химическая чистка и обработка } \\
\text { материала и волокон }\end{array}$ & $\begin{array}{l}\text { Канцерогенное воздействие, повреждения легких, } \\
\text { печени, гипотония }\end{array}$ \\
\hline
\end{tabular}

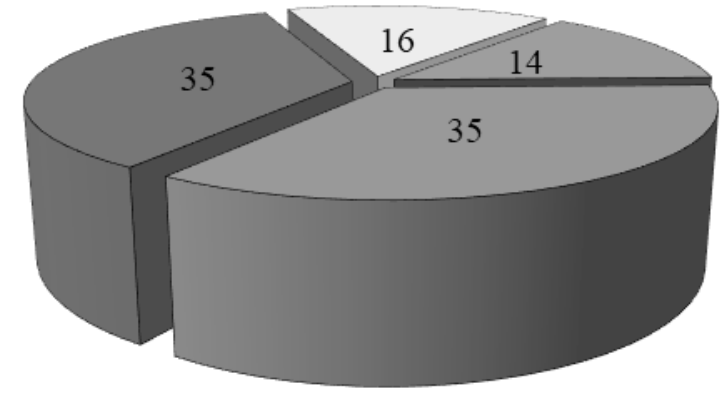

\section{$\square$ вещества в виде взвешенных частиц $\square$ соединения азота}

\section{口диоксид азота}

$\square$ оксид углерода

Рис. 1. Структура выбросов загрязняющих веществ в атмосферу предприятиями шерстяной промышленности,\% [3]

Перспективам использования экологобезопасных ресурсо- и энергосберегающих, безформальдегидных, а также перспективных нано-, био- и химических технологий при производстве шерстяных изделий посвящены труды Тасымбековой А.Н., Логиновой Л.В., Нурмаханкызы Н., Матниязова Г.К., Нурлыбаева А.Н., Adediran, Adeolu; Lemougna, Patrick N.; Yliniemi, Juho.

Однако несмотря на имеющиеся наработки, ряд вопросов, связанных с выбором такой технологии в шерстяном производстве, которая бы гарантировала не только выпуск экологически безопасной продукции, но и сделала невозможным или сводила к минимуму негативное вредное воздействие на здоровье человека и загрязнение окружающей среды (воздуха, воды, почв), остаются открытыми и требуют более детального анализа.

Таким образом, цель статьи заключается в проведении оценки влияния отходов предприятий шерстяного производства на окружающую среду.

К отходам шерстяной промышленности относят отходы производства шерстяных изделий в виде волокон, пряжи, нитей, лоскутов, обрезков материалов, а также отходы от красящих растворов при нанесении рисунка на изделия, отходы (воды) от промывки тех- нологического оборудования и самой шерсти, отходы от производства технических тканей в результате пропитки синтетическими растворами, отходы вымачивающего состава на основе резорцинформальдегидних смол, латекса и т.д.

Соответственно оценка влияния данных отходов на окружающую среду осуществляется в трех основных аспектах:

- загрязнение воздуха рабочей зоны при производстве продукции и распыление вредных веществ, используемых в ходе производства;

- загрязнение неорганическими и органическими веществами (красителями, тяжелыми металлами и т.д.) сточных вод предприятий;

- загрязнение почвы от сбора и временного складирования промышленных отходов. Основными побочными продуктами производства являются отходы шерсти, смесь смешанного мусора с растительными добавками. Однако влияние данной группы загрязняющих веществ на окружающую среду минимально.

В рамках первой группы анализируется состав, проводится оценка степени загрязнения и очистки воздуха из рабочих зон оборудования шерстяного производства. Существенным источником загрязне- 
ния воздушной среды также являются теплоэнергетические (котельные) установки предприятий. Известно, что основными полютантами, образующимися при сжигании твердого и жидкого топлива, является NOx и SO2. Также изучению подлежит степень и полнота улавливания отработанными растворами кислых компонентов дымовых газов с получением электролитов и повторным использованием их в производстве.

На рис. 1 представлена структура выброса загрязняющих веществ предприятий шерстяной промышленности в атмосферу.

Второй тип загрязнений, связанный со сбросами вредных веществ в водное пространство, предполагает оценку уровня очистки технологических сточных вод предприятий от красителей и тяжелых металлов. Как известно, по объему сбросов загрязненных сточных вод шерстяная промышленность занимает 8-9 место после энергетического комплекса. Содержание поверхностно-активных веществ в сточных водах ряда предприятий превышает предельно допустимые концентрации в 100-200 раз. Особенно это касается тех, которые осуществляют первичную обработку шерсти, они сбрасывают в водоемы в сутки столько загрязненных стоков, сколько сбрасывает город с населением 500 тыс. человек.
К наиболее опасным химическим загрязнителям вод в текстильном производстве следует отнести диоксины, присутствие которых связано с использованием для отбеливания шерсти водных растворов хлорида и гипохлорита натрия. Диоксины высоко токсичны, обладают мутагенным и канцерогенным действием и могут вызывать проблемы в области репродуктивного здоровья и развития, поражение иммунной системы, гормональные нарушения и раковые заболевания.

В таблице 1 представлена оценка вредного воздействия красителей и промывающих веществ шерстяной промышленности на примере типичных химических препаратов.

Резюмируя вышеизложенное, можно сделать следующие выводы. Предприятия шерстяной промышленности оказывают существенной влияние на окружающую среду. Для успешного решения экологических проблем необходимо повсеместное внедрение экологически адаптированных технологий, замкнутых технологических циклов и малоотходных производств, совершенствование технологических процессов, а также использование нового оборудования с меньшим уровнем выбросов, замена токсичных и биологически нерасщепляемых веществ нетоксичными и биологически расщепляемыми.

\section{ЛИТЕРАТУРА}

1. Armingeon, Klaus Trade-offs between redistribution and environmental protection: the role of information, ideology, and self-interest // Journal of European public policy. 2021. Volume 28: Number 4; pp 489-509.

2. Знаенко А.Б., Чадова И.Н. Экологическая культура в природоохранной деятельности // Молодежь, образование, наука, экология: сб. науч. трудов по материалам Всероссийской научно-практ. конф., посвященной Дню Российской науки. Ставрополь, 2021. С. 101-106.

3. Recycling from Waste in Fashion and Textiles: A Sustainable and Circular Economic Approach / Pintu Pandit, Shakeel Ahmed, Kunal Singha, Sanjay Shrivastava. Wiley-Scrivener, 2020. $496 \mathrm{p}$.

(c) Чадова Инна Николаевна ( innachadova@yandex.ru ). 